\section{BMJ Open Respiratory Research}

\title{
Variation in treatment preferences of pulmonary exacerbations among Australian and New Zealand cystic fibrosis physicians
}

\author{
Grace Currie (D) ,' Anna Tai, ${ }^{2,3,4}$ Tom Snelling, ${ }^{1,5,6,7}$ André Schultz ${ }^{4,8,9}$
}

To cite: Currie G, Tai A, Snelling $T$, et al. Variation in treatment preferences of pulmonary exacerbations among Australian and New Zealand cystic fibrosis physicians. BMJ Open Resp Res 2021;8:e000956. doi:10.1136/ bmjresp-2021-000956

- Additional online supplemental material is published online only. To view, please visit the journal online (http://dx.doi.org/10. 1136/bmjresp-2021-000956)

Received 9 April 2021 Accepted 15 May 2021

\section{Check for updates}

(C) Author(s) (or their employer(s)) 2021. Re-use permitted under CC BY-NC. No commercial re-use. See rights and permissions. Published by BMJ.

For numbered affiliations see end of article.

Correspondence to Dr André Schultz; andre.schultz@health.wa. gov.au

\section{ABSTRACT}

Background Despite advances in cystic fibrosis (CF) management and survival, the optimal treatment of pulmonary exacerbations remains unclear. Understanding the variability in treatment approaches among physicians might help prioritise clinical uncertainties to address through clinical trials.

Methods Physicians from Australia and New Zealand who care for people with CF were invited to participate in a web survey of treatment preferences for CF pulmonary exacerbations. Six typical clinical scenarios were presented; three to paediatric and another three to adult physicians. For each scenario, physicians were asked to choose treatment options and provide reasons for their choices.

Results Forty-nine CF physicians (31 paediatric and 18 adult medicine) participated; more than half reported $10+$ years of experience. There was considerable variation in primary antibiotic selection; none was preferred by more than half of respondents in any scenario. For secondary antibiotic therapy, respondents consistently preferred intravenous tobramycin and a third antibiotic was rarely prescribed, except in one scenario describing an adult patient. Hypertonic saline nebulisation and twice daily chest physiotherapy was preferred in most scenarios while dornase alfa use was more variable. Most CF physicians (>80\%) preferred to change therapy if there was no early response. Professional opinion was the most common reason for antibiotic choice.

Conclusions Variation exists among CF physicians in their preferred choice of primary antibiotic and use of dornase alfa. These preferences are driven by professional opinion, possibly reflecting a lack of evidence to base policy recommendations. Evidence from high-quality clinical trials is needed to inform physician decision making.

\section{INTRODUCTION}

Improving the management of pulmonary exacerbations among people with cystic fibrosis (CF) is an international research priority. ${ }^{1} \quad$ Pulmonary exacerbations are common and harmful; the mean number of hospital admissions due to pulmonary exacerbation is 0.9 per year per person. ${ }^{2}$ Exacerbations are associated with reduced quality of

\section{Key messages}

What is the variation in treatment preferences of Australian and New Zealand cystic fibrosis (CF) physicians for management of pulmonary exacerbations?

- Marked variation exists between CF physicians in treatment choices, particularly for primary antibiotics and use of dornase alfa, even when presented with the same clinical scenarios.

- This web survey of physician preferences highlights that treatment choices for CF exacerbations are mostly driven by professional opinion, reflecting a need for clinical trials.

life $^{3}$ and progressive lung function decline $\mathrm{e}^{4}$ with at least one-quarter of people failing to fully recover to baseline lung function after an exacerbation. ${ }^{5}$ Exacerbations are also associated with faster progression to death or lung transplant. ${ }^{4}$ Treatment of pulmonary exacerbations for hospitalised patients typically include intravenous antibiotics but robust evidence to inform antibiotic choices are lacking.

A recent Cochrane review reported inconclusive results in 40 trials analysing antibiotics for pulmonary exacerbations. ${ }^{6}$ In addition to specific antibiotic choice, physicians must also decide the method of antibiotic delivery (eg, intravenous or nebulised), duration of treatment and whether to switch or continue treatment if the patient is non-responsive to the prescribed regimen. Hence, robust evidence is lacking to guide choice of antibiotics. Physicians managing exacerbations also face many other treatment choices including the use of inhaled hypertonic saline, dornase alfa and systemic steroids. Robust evidence for the use of these treatments during pulmonary exacerbations are also lacking, thereby setting the stage for variation in treatment between different physicians and centres. 
Treatment regimens prescribed by physicians for pulmonary exacerbations of CF show substantial variation $^{7}$; such variation may well be warranted, as individual patient circumstances must be considered. Understanding physician treatment preferences may serve to identify ways to improve current practice guidelines across a range of clinical areas including CF. We deployed a single, electronic survey assessing physician preferences of treatment prescription for pulmonary exacerbations, based on different hypothetical patient scenarios.

\section{METHODS}

Design

Specialists in respiratory medicine responsible for the care of people with CF were invited to participate in a web-based survey assessing treatment preferences in the management of exacerbations between November 2018 and February 2019. Physicians were unable to participate if they normally resided outside of Australia (AUS) or New Zealand (NZ) or if they did not manage people with $\mathrm{CF}$ in recognised CF centres/hospitals.
An electronic web-based survey was developed assessing preferences for prescription of antibiotics, hypertonic saline, dornase alfa, steroids and physiotherapy for different clinical scenarios. The clinical scenarios were developed based on common presentations of patients being admitted to hospital for pulmonary exacerbations. The scenarios were written individually by two CF physicians (one adult CF physician; AT, and one paediatric CF physician; AS, in Perth, Western AUS) and reviewed by a further two physicians and a senior respiratory physiotherapist specialising in CF. Three different patient scenarios were developed for paediatric physicians and a further three for adult physicians (summary in table 1 with complete information in online supplemental file).

\section{Patient and public involvement}

An experienced consumer advisor with $\mathrm{CF}$ was consulted to ensure the survey captured common aspects of treatment for pulmonary exacerbations from a patient perspective. The results of the survey were also distributed to members of an Australian CF research consumer

\begin{tabular}{|c|c|c|c|}
\hline & Scenario 1 & Scenario 2 & Scenario 3 \\
\hline Paediatric & $\begin{array}{l}\text { A } 7 \text {-year-old girl with no } \\
\text { exacerbations for last } 2 \\
\text { years } \\
\text { No symptom improvement } \\
\text { after } 4 \text { weeks of oral } \\
\text { amoxicillin/clavulanic acid } \\
\text { and chest physiotherapy } \\
\text { FEV } \% \text { predicted is } \\
\text { reduced from } 105 \text { to } 90 \\
\text { Sputum culture 'mixed } \\
\text { oral flora' with no previous } \\
\text { results } \\
\text { Haemophilus influenzae } \\
\text { cultured from previous } \\
\text { throat swab } \\
\text { IgE levels undetectable }\end{array}$ & $\begin{array}{l}\text { A 12-year-old boy with wet cough for last } 5 \\
\text { weeks } \\
\text { Known colonisation with Pseudomonas } \\
\text { aeruginosa } \\
\text { No symptom improvement after nebulised } \\
\text { tobramycin } 300 \text { mb two times per day x4 } \\
\text { weeks } \\
\text { FEV } \% \text { predicted is reduced from } 85 \text { to } 74 \\
\text { IgE levels undetectable } \\
\text { Normal recent oral glucose test } \\
\text { Responded well to intravenous piperacillin/ } \\
\text { tazobactam and intravenous tobramycin } 6 \\
\text { months previously }\end{array}$ & $\begin{array}{l}\text { A 15-year-old boy with increased } \\
\text { wet cough, dyspnoea, lethargy } \\
\text { and low appetite } \\
\text { Known colonisation with } \\
\text { Staphylococcus aureus } \\
\text { Sputum culture: moderate growth } \\
\text { S. aureus sensitive to flucloxacillin } \\
\text { FEV \% predicted is reduced from } \\
65 \text { to } 50 \\
\text { IgE levels are } 100 \mathrm{kU} / \mathrm{L} \text { (stable) } \\
\text { Normal recent oral glucose test } \\
\text { Responded well to intravenous } \\
\text { cefepime and intravenous } \\
\text { tobramycin } 3 \text { months previously }\end{array}$ \\
\hline \multirow{4}{*}{ Adult } & $\begin{array}{l}\text { Shortness of breath, } \\
\text { increased chest tightness, } \\
\text { lethargy and weight loss }\end{array}$ & $\begin{array}{l}\text { CF-related diabetes } \\
\text { Chronically infected with } P \text {. aeruginosa } \\
\text { (multiresistant) }\end{array}$ & $\begin{array}{l}\text { FEV1\% predicted is reduced } \\
63 \text { to } 50 \text { ( } 2 \text { weeks ago and } \\
\text { unchanged) }\end{array}$ \\
\hline & $\begin{array}{l}(2.0 \mathrm{~kg}) \\
\text { Regular meds: Hypertonic } \\
\text { saline }\end{array}$ & $\begin{array}{l}\text { History of recurrent allergic } \\
\text { bronchopulmonary aspergillosis (treated } 2 \\
\text { years ago) }\end{array}$ & $\begin{array}{l}\text { Chronic } P \text {. aeruginosa infection. } \\
\text { Sputum culture: } P \text {. aeruginosa and } \\
\text { flucloxacillin susceptible } S \text {. aureus }\end{array}$ \\
\hline & $\begin{array}{l}\text { No regular airway } \\
\text { clearance/exercise }\end{array}$ & $\begin{array}{l}\text { IgE level was } 300 \mathrm{kU} / \mathrm{L} \text { (8 months ago) } \\
\text { Regular meds: azithromycin } 250 \text { mg daily, }\end{array}$ & $\begin{aligned} &(2 \text { weeks ago). } \\
& \text { Regular meds: azithromycin }\end{aligned}$ \\
\hline & $\begin{array}{l}\text { New crackles audible } \\
\text { over right middle lobe and }\end{array}$ & $\begin{array}{l}6 \% \text { Hypertonic saline daily, cyclical inhaled } \\
\text { dry powder tobramycin, nebulised colistin }\end{array}$ & $\begin{array}{l}250 \mathrm{mg} \text { daily, nebulised } 6 \% \\
\text { Hypertonic saline daily. }\end{array}$ \\
\hline
\end{tabular}

CF, cystic fibrosis; FEV1, forced expiratory volume in $1 \mathrm{~s}$; IgE, Immunoglobulin E. 
group to assist with a dissemination strategy. This reference group had 27 members including young people with $\mathrm{CF}$, adults with $\mathrm{CF}$ and caregivers of people with CF.

\section{Data collection and analysis}

Physicians were asked to provide basic demographic information and state whether they were responsible for the care of paediatric or adult patients. Participants were directed to either paediatric or adult clinical scenarios based on their field of practice. For each scenario, they were asked to prescribe treatment regimens from a list of treatment options and to state their reasons for primary and secondary antibiotic selection. They were also asked whether any of the antibiotic options presented were deemed unacceptable, and whether they would change any aspects of treatment if the patient in the scenario had a poor response to treatment after 7 days.

Antibiotic options were the same for all scenarios (table 2) and were presented in a random order for each participant to reduce bias. To minimise missing data, participants were required to answer each question before they could move onto the next. Surveys were anonymous; no identifying demographic information was captured, and IP address and email tracking were also disabled. Data collected from the survey was exported to an external electronic database and analysed using descriptive statistics (frequencies and percentages). For open text answers, themes were extracted to describe common responses. The survey was built and deployed using SurveyMonkey and sent to AUS and NZ CF centre directors (10 paediatric centres, 11 adult centres and 1 centre which is both a paediatric and adult centre) for internal distribution to other respiratory physicians. Approximately $60 \mathrm{CF}$ physicians were employed at these centres at the time of the study.

\section{RESULTS}

Fifty-three physicians accessed the introductory page of the web-survey; four of these physicians did not meet inclusion criteria or declined involvement, therefore, terminating the survey. Forty-nine physicians (31 paediatric and 18 adult) participated in the survey. Four surveys had incomplete data due to physicians exiting the survey before submitting responses. Thirty-nine physicians were from AUS and 10 from NZ. Residential states of the physicians were evenly distributed across Australian jurisdictions, with at least one physician represented from each state or territory, except the Northern Territory. More than half of respondents had 10 or more years of experience in managing people with $\mathrm{CF}$.

Preferences for the primary antibiotic varied across scenarios in both paediatric and adult physicians; no antibiotic was preferred by more than half of respondents (table 2). Among paediatric physicians, intravenous ceftazidime and intravenous piperacillin-tazobactam were the more popular primary antibiotic choices except in scenario 3 where most physicians chose intravenous cefepime. Notably, in this scenario, the patient had responded well to cefepime 3 months previously. Intravenous ciprofloxacin was never chosen as the primary antibiotic.

Among adult physicians, the primary antibiotic choice was most commonly intravenous ceftazidime or intravenous piperacillin-tazobactam. Intravenous cefepime, flucloxacillin and ceftriaxone and ciprofloxacin were rarely chosen as the primary antibiotic.

Most paediatric and adult physicians chose intravenous tobramycin as the secondary antibiotic for all scenarios. Prescription of a third antibiotic was not popular, except in adult scenario 2 where almost half $(44 \% ; 8 / 18)$ of respondents added a third antibiotic to the regimen, these being cotrimoxazole (6), azithromycin (1) and intravenous tobramycin (1). For this scenario, the patient cultured Stenotrophomonas and Pseudomonas, and azithromycin was part of his baseline treatment regimen.

Choosing dornase alfa was split approximately halfway between 'yes' and 'no' in most clinical scenarios, except for the adult scenario 2 where the patient had new haemoptysis. Similarly, most physicians preferred hypertonic saline nebulisation and twice daily chest physiotherapy for all scenarios except adult scenario 2 (with new haemoptysis). For this scenario, chest physiotherapy frequency preference was almost equally split between twice daily chest physiotherapy and reduced frequency (ie, once daily) or no chest physiotherapy. A short course of oral prednisolone was almost never used by paediatric or adult physicians.

Antibiotic choices were mostly influenced by the professional/clinical opinion of the physician (figure 1). More paediatric physicians relied on hospital or department policy when choosing antibiotics compared with adult physicians. A small proportion of paediatric physicians selected 'other' reason for their prescription; themes included targeting the type of organism cultured (8), previous favourable patient response to antibiotics (5), using national antibiotic prescription guidelines (1) and treatment effects on nontuberculous mycobacteria (1). Most physicians indicated they would change management for all scenarios following poor patient response. Common themes for changing management included antibiotic prescription, repeat or additional investigations (eg, sputum culture, imaging, bronchoscopy), adding additional treatments (eg, hypertonic saline) and screening for allergic bronchopulmonary aspergillosis.

Most physicians selected at least one antibiotic option as being unacceptable (69\% vs 31\%). These options were most commonly intravenous gentamicin, intravenous colistin, intravenous ciprofloxacin, intravenous ceftriaxone and intravenous amikacin. Concerns about antibiotic toxicity, preference for oral formulations with bioavailability equivalence, the availability of good inhaled formulations of the same antibiotic class, and the lack of effectiveness against Pseudomonas aeruginosa were provided as reasons. Detailed responses can be found in online supplemental file. 
Table 2 Selected treatment prescriptions for patient scenarios among paediatric and adult physicians

\begin{tabular}{|c|c|c|c|c|c|c|}
\hline & \multicolumn{3}{|c|}{ Paediatric physicians } & \multicolumn{3}{|c|}{ Adult physicians } \\
\hline & Scenario 1 & Scenario 2 & Scenario 3 & Scenario 1 & Scenario 2 & Scenario 3 \\
\hline & $\begin{array}{l}\mathrm{N}=30 \\
(1 \text { missing) }\end{array}$ & $\begin{array}{l}\mathrm{N}=29 \\
(2 \text { missing) }\end{array}$ & $\begin{array}{l}\mathrm{N}=28 \\
\text { (3 missing) }\end{array}$ & $\mathrm{N}=18$ & $\mathrm{~N}=18$ & $\begin{array}{l}\mathrm{N}=17 \\
\text { (1 missing) }\end{array}$ \\
\hline \multicolumn{7}{|l|}{ Primary antibiotic } \\
\hline Intravenous ceftazidime & $11(37 \%)$ & $13(45 \%)$ & $1(4 \%)$ & $7(39 \%)$ & $8(44 \%)$ & $8(47 \%)$ \\
\hline Intravenous ceftriaxone & $7(23 \%)$ & 0 & $4(14 \%)$ & $2(11 \%)$ & 0 & 0 \\
\hline Intravenous ciprofloxacin & 0 & 0 & 0 & 0 & 0 & 0 \\
\hline Intravenous piperacillin-tazobactam & $8(27 \%)$ & $14(48 \%)$ & $5(18 \%)$ & $6(33 \%)$ & $8(44 \%)$ & $6(35 \%)$ \\
\hline Intravenous flucloxacillin & $1(3 \%)$ & 0 & $6(21 \%)$ & 0 & 0 & $1(6 \%)$ \\
\hline Intravenous cefepime & $1(3 \%)$ & $1(3 \%)$ & $12(43 \%)$ & $1(6 \%)$ & $1(6 \%)$ & $1(6 \%)$ \\
\hline Other & $2(7 \%)$ & $1(3 \%)$ & 0 & $2(11 \%)$ & $1(6 \%)$ & $1(6 \%)$ \\
\hline \multicolumn{7}{|l|}{ Secondary antibiotic } \\
\hline None & $7(23 \%)$ & 0 & $3(11 \%)$ & $4(22 \%)$ & 0 & 0 \\
\hline Intravenous tobramycin & $18(60 \%)$ & $27(93 \%)$ & $21(75 \%)$ & $13(72 \%)$ & $15(83 \%)$ & $13(76 \%)$ \\
\hline Intravenous colistin & $1(3 \%)$ & 0 & 0 & 0 & 0 & 0 \\
\hline Intravenous gentamicin & $1(3 \%)$ & 0 & 0 & 0 & 0 & 0 \\
\hline Intravenous amikacin & 0 & 0 & 0 & 0 & 0 & 0 \\
\hline Inhaled tobramycin & 0 & $1(3 \%)$ & 0 & $1(6 \%)$ & $2(11 \%)$ & $2(12 \%)$ \\
\hline Inhaled colistin & 0 & $1(3 \%)$ & 0 & 0 & 0 & 0 \\
\hline Intravenous ciprofloxacin & 0 & 0 & 0 & 0 & 0 & 0 \\
\hline Oral ciprofloxacin & 0 & 0 & 0 & 0 & 0 & 0 \\
\hline Other & $3(10 \%)$ & 0 & $4(14 \%)$ & 0 & $1(6 \%)$ & $2(12 \%)$ \\
\hline \multicolumn{7}{|l|}{ Reason for antibiotic selection } \\
\hline Professional opinion/clinical experience & $11(37 \%)$ & $12(41 \%)$ & $15(54 \%)$ & $12(66 \%)$ & $13(72 \%)$ & $12(70 \%)$ \\
\hline Hospital or department policy & $7(23 \%)$ & $8(28 \%)$ & $5(18 \%)$ & $1(6 \%)$ & $2(11 \%)$ & $2(12 \%)$ \\
\hline Advice from colleagues & $3(10 \%)$ & 0 & 0 & 0 & 0 & 0 \\
\hline Availability of medication & $2(7 \%)$ & 0 & 0 & $1(6 \%)$ & $2(11 \%)$ & $1(6 \%)$ \\
\hline Concern for side effects & 0 & 0 & $1(3 \%)$ & 0 & 0 & 0 \\
\hline Clinical familiarly with treatment & $3(10 \%)$ & $3(10 \%)$ & $2(7 \%)$ & $1(6 \%)$ & $1(6 \%)$ & $2(12 \%)$ \\
\hline Other & $4(13 \%)$ & $6(21 \%)$ & $5(18 \%)$ & $3(16 \%)$ & 0 & 0 \\
\hline \multicolumn{7}{|l|}{ Third antibiotic } \\
\hline No & $29(97 \%)$ & $27(93 \%)$ & $23(82 \%)$ & $18(100 \%)$ & $10(56 \%)$ & $14(82 \%)$ \\
\hline Yes & $1(3 \%)$ & $2(7 \%)$ & $5(18 \%)$ & 0 & $8(44 \%)$ & $3(18 \%)$ \\
\hline \multicolumn{7}{|l|}{ Chest physiotherapy } \\
\hline No & $1(3 \%)$ & 0 & 0 & 0 & $3(17 \%)$ & 0 \\
\hline Yes, daily & $1(3 \%)$ & $1(3 \%)$ & $1(4 \%)$ & $3(17 \%)$ & $5(28 \%)$ & $3(18 \%)$ \\
\hline Yes, BD & 27 (90.00\%) & $26(90 \%)$ & $24(86 \%)$ & $14(78 \%)$ & $9(50 \%)$ & $12(70 \%)$ \\
\hline Yes, three times a day & $1(3 \%)$ & $2(7 \%)$ & $3(10 \%)$ & $1(5 \%)$ & $1(6 \%)$ & $2(12 \%)$ \\
\hline \multicolumn{7}{|l|}{ Dornase alfa } \\
\hline Yes & $12(40 \%)$ & 22 (76\%) & $19(68 \%)$ & $9(50 \%)$ & $3(17 \%)$ & $10(59 \%)$ \\
\hline No & $18(60 \%)$ & $7(24 \%)$ & $9(32 \%)$ & $9(50 \%)$ & $15(83 \%)$ & $7(41 \%)$ \\
\hline \multicolumn{7}{|l|}{ Hypertonic saline } \\
\hline Yes & $24(80 \%)$ & $25(86 \%)$ & $26(93 \%)$ & $16(89 \%)$ & 7 (39\%) & $16(94 \%)$ \\
\hline No & $6(20 \%)$ & $4(14 \%)$ & 2 (7\%) & 2 (11\%) & $11(61 \%)$ & $1(6 \%)$ \\
\hline
\end{tabular}




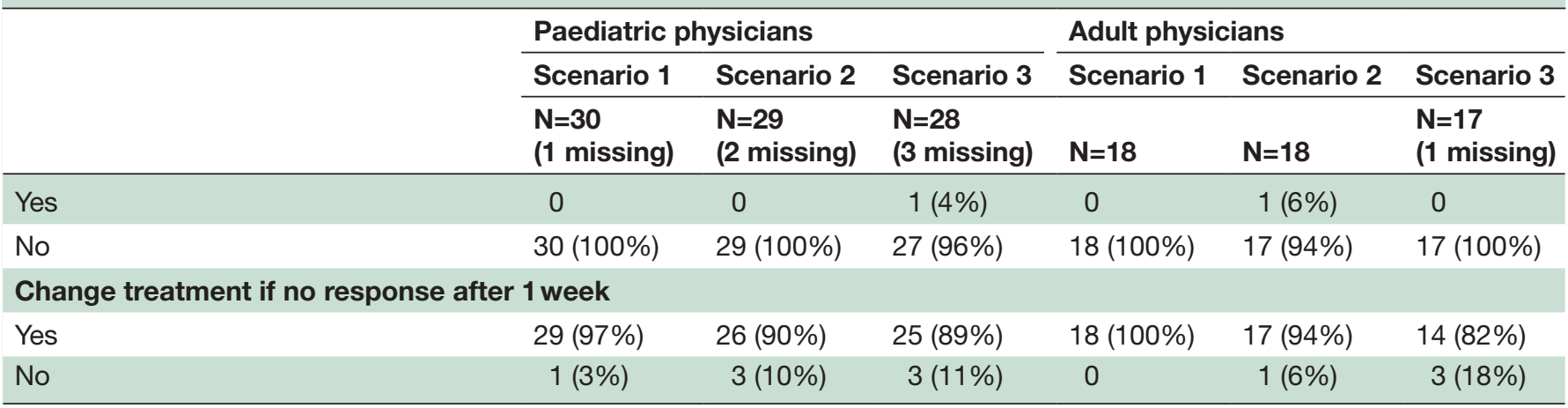

BD, two times per day.

\section{DISCUSSION}

In summary, treatment preferences for exacerbations of CF varied markedly between respiratory physicians, even when presented with the same clinical scenarios. This variation is not surprising given there are no specific antibiotic consensus guidelines and a paucity of high-quality evidence from clinical trials to assist decision-making. Variation in preferences for managing exacerbations was also reported in a recent survey of US CF physicians. ${ }^{8}$ This study reported wide variation between and within $\mathrm{CF}$ centres, and even within the same clinician for prescription of oral vs intravenous antibiotics for different clinical scenarios. Our survey adds to this knowledge; variation still exists even when clinical scenarios clearly define that the patient was experiencing an exacerbation. Our survey also asked physicians to specify treatment preferences

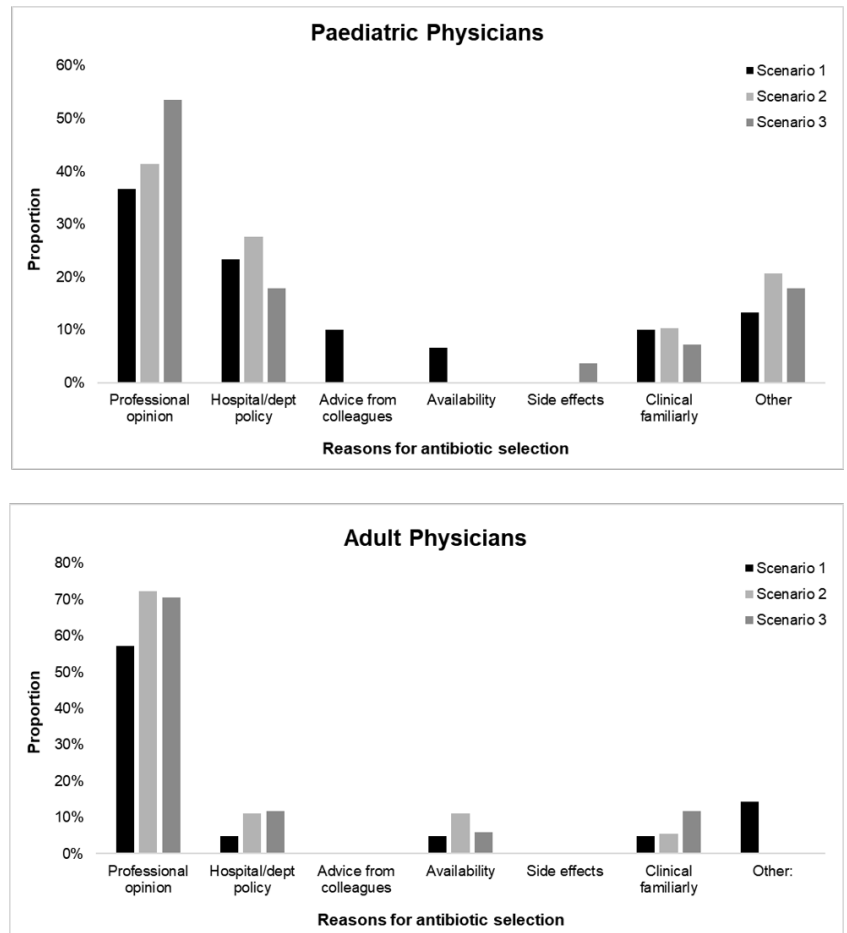

Figure 1 Differences in proportions of reasons given for antibiotics prescription among paediatric and adult physicians. for patients who were sick enough to be admitted to hospital. Surveys analysing antibiotic preferences among physicians have also been administered in other settings including treating sepsis in intensive care ${ }^{9}$ and childhood pneumonia. ${ }^{10}$ These surveys reported that preferences were largely geographical ${ }^{10}$ and tended to deviate from Australian prescribing guidelines when there was uncertainty about antibiotic resistance. ${ }^{9}$

Variation in treatment is not always undesirable; antibiotic combinations for treatment of pulmonary exacerbations of $\mathrm{CF}$ are influenced by a range of factors, including the organism detected in culture analysis, previous patient response, known allergy, local policy and access, ${ }^{11}$ as well as the professional opinion of the physician. In vitro antibiotic susceptibility testing is also used, ${ }^{11}$ although a recent study suggested that patient response is considered more important compared with susceptibility testing when deciding treatment. ${ }^{12}$ Other important considerations in the choice of antibiotics are side effects, which may include renal toxicity, hepatic toxicity and ototoxicity, and concerns about increased antimicrobial resistance. ${ }^{6}$ Hence, variation in treatment could, at times, reflect personalised care. However, when variation of care cannot be explained by patient need or preference, such as seen in our study, then the variation is unwarranted. Unwarranted variation suggests that patients are not receiving optimal care and are at risk of harm. ${ }^{13}$

With regard to primary antibiotic selection in our survey, no option was preferred by more than half of respondents in any clinical scenario. Findings from a 2015 Cochrane review reported no difference in forced expiratory volume in $1 \mathrm{~s}$ between single versus combined antibiotic therapy for exacerbations in CF. ${ }^{6}$ Importantly, antibiotic susceptibility testing lacks predictive value in the context of a pulmonary exacerbation (eg, patients may improve irrespective of being treated with antibiotics to which in vitro testing suggest resistance). Additionally, patients may not respond to antibiotic therapy even when in vitro testing of airway cultures suggest sensitivity to the antibiotics being used. ${ }^{14-16}$ Hence, some CF physicians tend to place less value on antibiotic susceptibility testing. ${ }^{12}$ A reduction in susceptibility testing at CF centres does not appear to be associated with worse clinical outcomes. ${ }^{17}$ 
The widespread acceptance of intravenous tobramycin as the secondary antibiotic of choice for all scenarios is interesting as it was consistently used irrespective of airway culture results. Intravenous tobramycin may have been preferred above intravenous gentamicin due to concerns about potential increased side effects with gentamicin. ${ }^{18}$ A previous randomised controlled trial suggested that tobramycin monotherapy is as effective as combination therapy in restoring pulmonary function following exacerbations. ${ }^{19}$ However, this study has not been replicated and had several limitations including low sample size. Recent guidelines suggest there is insufficient evidence to support the use of aminoglycoside monotherapy over combination therapy for treating exacerbations. ${ }^{20}$

Most physicians preferred patients to perform twice daily chest physio for all scenarios, except in the scenario where the patient had new haemoptysis. Typically in AUS and NZ, patients are advised to perform regular airway clearance techniques (ACT) once or twice a day depending on their individual circumstances. Mild to moderate new haemoptysis may result in continuation of ACT with modifications (eg, reduction in cough force) or temporary cessation of physio for a short period depending on site protocols. ${ }^{21} \mathrm{~A}$ recent cross-sectional survey in AUS reported that $58 \%$ of people with CF perform regular airway clearance daily, often increasing to twice daily or more when unwell. ${ }^{22}$ Further increased frequency of airway clearance might be beneficial for patients hospitalised for exacerbations. However, given the time-burden associated with $\mathrm{CF}$ treatments, more evidence is required to understand how frequency of airway clearance during exacerbations may impact longterm outcomes.

While most physicians nominated professional opinion as a reason for their choices, decision making among our sample appears to be based on many different and complex clinical factors. In paediatric scenarios 2 and 3 , physicians were given a history of the patient having a prior good response to intravenous piperacillintazobactam and intravenous cefepime, respectively. Primary antibiotic choice was more likely to favour these options in these scenarios, indicating that a previous favourable patient response may be an important factor in prescribing antibiotic options. The preference for intravenous cefepime only occurred in the scenario where it was mentioned that the patient previously had a good response to this option. We did not include 'patient response' as a distinct reason for antibiotic choice and including this option may have given different results.

\section{Strengths and limitations}

Overall, our survey had good representation from respiratory physicians across almost all jurisdictions of AUS and NZ. A limitation of this study was measuring preferences for exacerbation treatment in only AUS and NZ physicians; generalisability of preferences may vary in other countries. However, if the lack in consistency reflects a lack of evidence then marked variation in prescribing practice will likely be universal. Different aspects of variation in practice have been well described across the USA and Canada. ${ }^{823}{ }^{24}$ We presented three hypothetical scenarios to paediatric and three different scenarios to adult physicians; different scenarios may have resulted in different treatment selections. Our scenarios were written to be representative of common clinical presentations that reflect the complexity of typical patient symptoms, and comorbidities.

Verifying physician preferences determined by electronic survey with actual prescription behaviour was not possible due to delays in reporting and what data is currently being captured. The Australian Cystic Fibrosis Data Registry (https://www.cysticfibrosis.org. $\mathrm{au} /$ dataregistry) records frequency of hospitalisations, whether intravenous antibiotics were prescribed and duration of treatment; details on type of antibiotics prescribed are not recorded. However, the patient scenarios were designed to be reflective of Australian practice and no participant gave feedback in their responses to suggest otherwise. Overall, the study results are concerning and suggest the need for high quality research to inform the management of pulmonary exacerbations.

Recent findings from the STOP study report similar variation in exacerbation management across the USA. Notably, physicians appear to be highly supportive of enrolling their patients into studies comparing antibiotic combinations, duration of treatment and other interventions to understand optimal management. ${ }^{25}$ Our survey did not measure preferences for duration of treatment. The median duration of intravenous therapy given in hospital to people with CF in AUS was 14 days in 2019. ${ }^{26}$ Recent results from the STOP2 study might challenge clinician preferences. The study, which randomised participants to different durations of intravenous treatment, reported that a 10 day duration was not inferior to a 14-day duration of treatment in regards to absolute change in lung function. ${ }^{27}$

Although exacerbation frequency might reduce in the short term due to COVID-19-related social distancing, and over time due to the use of cystic fibrosis transmembrane conductance regulator (CFTR) modulators, there will remain a sizeable proportion of people with $\mathrm{CF}$ who are not eligible, or have difficulty accessing treatments due to barriers in insurance coverage or government subsidised programmes. Non-adherence to treatment will remain a problem for some. Thus, hospitalisation for pulmonary exacerbation treatment will still be required in the future. Answering the large number of questions around the treatment of pulmonary exacerbations of $\mathrm{CF}$ will require a multitude of traditional clinical trials. Novel trial designs offer the potential for faster and more efficient ways of optimising CF management. ${ }^{28}$ 


\section{SUMIMARY}

In conclusion, our study suggests that there is wide variation in exacerbation management preferences, especially in primary antibiotics and use of other treatments like dornase alfa. This marked variation exists even when physicians are presented with the same typical patient scenarios seen in CF clinics and when case scenarios are clearly defined as a pulmonary exacerbation requiring in-hospital management. Preferences for treatment are mostly influenced by the professional opinion of the clinician. As variation in care is associated with variation in outcomes; consistent management across centres based on robust evidence from randomised trials is critically needed.

\section{Author affiliations}

${ }^{1}$ Wesfarmers Centre of Vaccines and Infectious Diseases, Telethon Kids Institute, Nedlands, Western Australia, Australia

${ }^{2}$ Department of Respiratory Medicine, Sir Charles Gairdner Hospital, Nedlands, Western Australia, Australia

${ }^{3}$ Institute for Respiratory Health, Nedlands, Western Australia, Australia ${ }^{4}$ School of Medicine, The University of Western Australia Faculty of Medicine Dentistry and Health Sciences, Perth, Western Australia, Australia ${ }^{5}$ Department of Infectious Diseases, Perth Children's Hospital, Nedlands, Western Australia, Australia

${ }^{6}$ School of Public Health, Curtin University, Perth, Western Australia, Australia ${ }^{7}$ Menzies School of Health Research, Charles Darwin University, Darwin, Northern Territory, Australia

${ }^{8}$ Department of Respiratory Medicine, Perth Children's Hospital, Nedlands, Western Australia, Australia

${ }^{9}$ Respiratory Health, Telethon Kids Institute, Nedlands, Western Australia, Australia

Acknowledgements The authors would like to thank all physicians that took part in the survey and CF Centre Directors who distributed the survey among their internal networks.

Contributors GEC participated in the survey and study design, analysis, sought ethics approval and wrote the first draft of the manuscript. AT and TS participated in the survey and study design and writing of the manuscript. AS participated in the survey and study design, analysis and had overall responsibility of the manuscript.

Funding This survey was supported by funding provided by the Medical Research Future Fund Lifting Clinical Trials and Registries Capacity Grant (GNT1152376).

Competing interests AS received honorarium funds from Vertex Pharmaceuticals for being on an advisory panel. GEC, AT and TS have no conflicts of interest to declare.

Patient consent for publication Not required.

Ethics approval The study was approved by the Human Research Ethics Committee of the University of Western Australia (Ref: RA/4/20/4914).

Provenance and peer review Not commissioned; externally peer reviewed.

Data availability statement Data are available on reasonable request. Summary-level trial results will be shared, and individual participant data can be requested subject to necessary HREC approvals. As a minimum, data sharing will include deidentified participant data including survey type and responses to case scenarios. Individual responses to open text answers have been included in online supplemental material.

Supplemental material This content has been supplied by the author(s). It has not been vetted by BMJ Publishing Group Limited (BMJ) and may not have been peer-reviewed. Any opinions or recommendations discussed are solely those of the author(s) and are not endorsed by BMJ. BMJ disclaims all liability and responsibility arising from any reliance placed on the content. Where the content includes any translated material, BMJ does not warrant the accuracy and reliability of the translations (including but not limited to local regulations, clinical guidelines, terminology, drug names and drug dosages), and is not responsible for any error and/or omissions arising from translation and adaptation or otherwise.

Open access This is an open access article distributed in accordance with the Creative Commons Attribution Non Commercial (CC BY-NC 4.0) license, which permits others to distribute, remix, adapt, build upon this work non-commercially, and license their derivative works on different terms, provided the original work is properly cited, appropriate credit is given, any changes made indicated, and the use is non-commercial. See: http://creativecommons.org/licenses/by-nc/4.0/.

ORCID iD

Grace Currie http://orcid.org/0000-0003-2984-5210

\section{REFERENCES}

1 Rowbotham NJ, Smith S, Leighton PA, et al. The top 10 research priorities in cystic fibrosis developed by a partnership between people with CF and healthcare providers. Thorax 2018;73:388-90.

2 Australian Cystic Fibrosis Data Registry. Cystic fibrosis in Australia 2014: 17th annual report from the Australian cystic fibrosis data registry, 2016. Available: https://www.cysticfibrosis.org. au/getmedia/769b5fbd-8ae6-4822-9b16-d1a804b0cf78/CFA DataRegistryReport 2014 Final.pdf.aspx

3 Britto MT, Kotagal UR, Hornung RW, et al. Impact of recent pulmonary exacerbations on quality of life in patients with cystic fibrosis. Chest 2002;121:64-72.

4 de Boer K, Vandemheen KL, Tullis E, et al. Exacerbation frequency and clinical outcomes in adult patients with cystic fibrosis. Thorax 2011;66:680-5

5 Sanders DB, Bittner RCL, Rosenfeld M, et al. Failure to recover to baseline pulmonary function after cystic fibrosis pulmonary exacerbation. Am J Respir Crit Care Med 2010;182:627-32.

6 Hurley MN, Prayle AP, et al, review co-authors. Intravenous antibiotics for pulmonary exacerbations in people with cystic fibrosis. Paediatr Respir Rev 2015;16:246-8.

7 West NE, Beckett VV, Jain R, et al. Standardized treatment of pulmonary exacerbations (stop) study: physician treatment practices and outcomes for individuals with cystic fibrosis with pulmonary exacerbations. J Cyst Fibros 2017;16:600-6.

8 Kraynack NC, Gothard MD, Falletta LM, et al. Approach to treating cystic fibrosis pulmonary exacerbations varies widely across US CF care centers. Pediatr Pulmonol 2011;46:870-81.

9 Dulhunty JM, Webb SAR, Paterson DL, et al. A survey of antibiotic prescribing practices in Australian and New Zealand intensive care units. Crit Care Resusc 2010;12:162-70.

10 Bielicki JA, Barker CIS, van der Velden AW, et al. Antibiotic preferences for childhood pneumonia vary by physician type and European region. ERJ Open Res 2016;2. doi:10.1183/23120541.00001-2016. [Epub ahead of print: 2904 2016].

11 Plummer A, Wildman M. Duration of intravenous antibiotic therapy in people with cystic fibrosis. The Cochrane database of systematic reviews 2013;5:Cd006682

12 Zemanick E, Burgel P-R, Taccetti G, et al. Antimicrobial resistance in cystic fibrosis: a Delphi approach to defining best practices. J Cyst Fibros 2020;19:370-5.

13 Duggan A, Koff E, Marshall V. Clinical variation: why it matters. Med J Aust 2016;205:S3-4.

14 Chmiel JF, Aksamit TR, Chotirmall SH, et al. Antibiotic management of lung infections in cystic fibrosis. I. The microbiome, methicillinresistant Staphylococcus aureus, gram-negative bacteria, and multiple infections. Ann Am Thorac Soc 2014;11:1120-9.

15 Smith AL, Fiel SB, Mayer-Hamblett N, et al. Susceptibility testing of Pseudomonas aeruginosa isolates and clinical response to parenteral antibiotic administration: lack of association in cystic fibrosis. Chest 2003;123:1495-502.

16 Somayaji R, Parkins MD, Shah A, et al. Antimicrobial susceptibility testing (AST) and associated clinical outcomes in individuals with cystic fibrosis: a systematic review. J Cyst Fibros 2019;18:236-43.

17 Etherington C, Hall M, Conway S, et al. Clinical impact of reducing routine susceptibility testing in chronic Pseudomonas aeruginosa infections in cystic fibrosis. J Antimicrob Chemother 2008;61:425-7.

18 Smyth A, Lewis S, Bertenshaw C, et al. Case-Control study of acute renal failure in patients with cystic fibrosis in the UK. Thorax 2008;63:532-5

19 Master V, Roberts GW, Coulthard KP, et al. Efficacy of once-daily tobramycin monotherapy for acute pulmonary exacerbations of cystic fibrosis: a preliminary study. Pediatr Pulmonol 2001:31:367-76.

20 Flume PA, Mogayzel PJ, Robinson KA, et al. Cystic fibrosis pulmonary guidelines. Am J Respir Crit Care Med 2009;180:802-8.

21 Button BM, Wilson C, Dentice R, et al. Physiotherapy for cystic fibrosis in Australia and New Zealand: a clinical practice guideline. Respirology 2016;21:656-67. 
22 Ward N, Stiller K, Holland AE, et al. Exercise is commonly used as a substitute for traditional airway clearance techniques by adults with cystic fibrosis in Australia: a survey. J Physiother 2019;65:43-50.

23 Schechter MS, Regelmann WE, Sawicki GS, et al. Antibiotic treatment of signs and symptoms of pulmonary exacerbations: a comparison by care site. Pediatr Pulmonol 2015;50:431-40.

24 Schechter MS. Nongenetic influences on cystic fibrosis outcomes. Curr Opin Pulm Med 2011;17:448-54.

25 West NE, Beckett VV, Jain R, et al. Standardized treatment of pulmonary exacerbations (STOP) study: physician treatment practices and outcomes for individuals with cystic fibrosis with pulmonary exacerbations. J Cyst Fibros 2017;16:600-6.
26 Australian Cystic Fibrosis Data Registry. Annual report 2019, 2020. Available: https://www.cysticfibrosis.org.au/getmedia/bcab56d95bbe-4b19-9486-85a0ad2c2a21/ACFDR-2019-Annual-Report.pdf. aspx

27 Goss C. Standardized treatment of pulmonary exacerbations II (STOP2). Available: https://clinicaltrials.gov/ct2/show/results/ NCT02781610

28 Schultz A, Marsh JA, Saville BR, et al. Trial Refresh: a case for an adaptive platform trial for pulmonary exacerbations of cystic fibrosis. Front Pharmacol 2019;10:301 